\title{
Dzieci, rodzice i wyrwy w murze
}

\author{
Gałuszka, D. (2017). Gry wideo w środowisku rodzinnym. \\ Diagnoza i rekomendacje. Kraków: Libron.
}

\section{Abstrakt:}

Gry wideo od dłuższego czasu należą do najpopularniejszych mediów. Są łatwo dostępne, masowo przenikają do powszechnej świadomości i rzeczywistej przestrzeni - czy to w formie rozrywki, obecności za sprawą reklam, czy stanowisk rządów wobec branży gier. Fenomen tego medium dotyka poszczególnych sektorów życia jednostki, w tym rodziny. To właśnie podstawowa komórka społeczna okazuje się polem do prowadzenia interesujących badań nad wpływem gier wideo na młodych odbiorców. Damian Gałuszka w swojej książce Gry wideo w środowisku rodzinnym. Diagnoza i rekomendacje (2017) posuwa się jeszcze dalej - wskazuje, za pomocą refleksji nad grami, na współczesne problemy polskich rodzin oraz odkrywa, stosując socjologiczne analizy, stan świadomości i sposób myślenia polskich rodziców.

\section{Słowa kluczowe:}

Damian Gałuszka, edukacja medialna, gry wideo, rodzina, socjologia

\section{Children, Parents, and Breaches in the Wall}

\section{Gałuszka, D. (2017). Gry wideo w środowisku rodzinnym. Diagnoza}

i rekomendacje. Kraków: Libron.

\section{Abstract:}

Video games have been one of the most popular media for a long time. They are easily accessible and appear massively in the general consciousness and real space - whether in the form of entertainment, presence through ads, or government programmes supporting gaming industry. The phenomenon of this medium affects many sectors of the individual's life, including the family. It is the basic social unit that turns out to be a field for interesting research on the impact of video games on young audiences. Damian Gałuszka in his book Gry wideo w środowisku rodzinnym

* Adam Flamma - dr, pracuje na Wydziale Nauk Społecznych i Technicznych w Dolnośląskiej Szkole Wyższej. Jego zainteresowania badawcze obejmują kulturowe oraz komunikacyjne aspekty gier wideo, ich historię oraz personologię. Kontakt: adam.flamma@dsw.edu.pl. 
Diagnoza i rekomendacje [Video Games in a Family Environment: Diagnosis and Recommendations] (2017) goes even further - he indicates the contemporary problems of Polish families with the help of games and discovers, using sociological analyses, the state of awareness and the way of thinking of Polish parents.

\section{Key words:}

Damian Gałuszka, media education, video games, family, sociology

G ry to jeden z najważniejszych artefaktów współczesności. Komputerowe, konsolowe, mobilne (zbiorczo nazywane po prostu grami wideo lub, przyjmując za skandynawską szkołą badania gier ${ }^{1}$, grami cyfrowymi), logiczne, planszowe, terenowe - wszystkie stanowią ważny element kultury popularnej XXI wieku i są przy tym istotnym sektorem światowych i krajowych przemysłów $^{2}$. W związku z tym funkcjonują one coraz śmielej w różnych przestrzeniach naszego życia. Dotyczy to szczególnie gier wideo wykorzystywanych w medycynie, terapii czy od dłuższego czasu w militariach (Michael, Chen, 2005, s. 66-70, 179-197). Z uwagi na powszechność medium, oczywiste jest, że gry wideo funkcjonują również w społeczeństwie, co szczególnie uwidacznia się na przykładzie rodziny jako podstawowej komórki społecznej³

Multimedialna rozrywka jest popularna zarówno wśród dzieci, jak i dorosłych - rodziców, którzy albo sami są czynnymi graczami, albo byli nimi w przeszłości, nierzadko w okresie swojej młodości. W związku z tym, że gry wideo stanowiły lub wciąż stanowią element wspólny dla obu pokoleń - rodziców i ich dzieci, mogą one przydać się w budowaniu wzajemnej relacji lub jej zacieśnianiu. Nie oznacza to jednak, że obecnie gry są traktowane tylko i wyłącznie jako międzypokoleniowe spoiwo. Wręcz przeciwnie, niekiedy wciąż można spotkać się z przekonaniem, że jest to niepoważna i niezrozumiała rozrywka,

1 Taka definicja gier przyjęta jest np. przez najbardziej wpływową organizację zrzeszającą badaczy gier - DiGRA (b.d.), czyli Digital Games Research Association.

2 Świadczą o tym chociażby wyniki przedstawiane w branżowych raportach. Więcej o ostatnich danych polskiej branży gier wideo - całościową wartość rynku oraz procent PKB, który stanowi - można znaleźć w opracowaniu Kondycja polskiej branży gier '17. Raport 2017 (Bobrowski, Rudzińska-Szary, Krampus-Sepielak, Śliwiński, Rudnicki, 2017).

3 Interesujący pod tym względem może być amerykański raport Teens, Video Games, and Civics: Teens' Gaming Experiences Are Diverse and Include Significant Social Interaction and Civic Engagement (Lenhart, Kahne, Middaugh, Macgill, Evans, Vitak, 2008), który kompleksowo ukazuje spectrum wpływu medium na młodych ludzi oraz ich relacje społeczne. 
charakterystyczna wyłącznie dla młodego pokolenia ${ }^{4}$. Taki pogląd jest coraz rzadszy, jednak wciąż funkcjonuje, również w Polsce. Owo przekonanie wpisuje się w szereg popularnych niegdyś stereotypów na temat gier wideo, które to uogólnienia dziś są już nieco archaiczne, jednak wciąż można znaleźć przejawy tego rodzaju generalizacji (Marczak, 2018). Stereotypy te dotyczą przemocy w grach, uzależnienia oraz „głupiej rozrywki”, pozbawionej sensu, a przy tym wywołującej agresję i odizolowanie od rzeczywistości. Dlatego też istotne wydaje się zadanie, o którym w swojej rozprawie Gry wideo w środowisku rodzinnym. Diagnoza i rekomendacje pisze Damian Gałuszka (2017): „Zasadniczym celem tej książki jest pokazanie gier wideo jako medium, które odpowiednio wykorzystane oferuje czas »dla nas«, tzn. wspólny czas dzieci i rodziców, który z pewnością nie jest zmarnowany" (s. 12).

Te słowa oddają rzeczywistą intencję autora, jednocześnie sygnalizują jednak specyficzny dylemat poznawczy. Przede wszystkim dlatego, że publikacja posiada cechy typowego toolkitu dla rodziców, czyli zestawu pomysłów i sugestii dobrych praktyk, jak korzystać z gier wideo. Jednakże autor sam zwraca uwagę, iż właściwie nie to jest jego celem. Jak tłumaczy:

Chciałem raczej wysunąć na pierwszy plan stosunkowo wąskie zagadnienie obecności gier wideo w życiu rodziny, skupiając się na wyartykułowanych przez samych zainteresowanych (rodziców) konsekwencjach tej obecności. W następnym kroku zgromadzona wiedza stała się punktem wyjścia dla badań jakościowych, których efektem jest szereg wniosków i praktycznych zaleceń wychowawczych, osadzających się w środowisku życia pewnej konkretnej grupy rodzin (Gałuszka, 2017, s. 17).

I rzeczywiście, treść pracy ukazuje możliwe funkcjonowanie gier wideo w polskiej rodzinie, co wszakże w połączeniu $z$ awizowanym wcześniej celem utrudnia jednoznaczne określenie przesłania autora czy może raczej czyni je nieco mglistym. Niemniej jednak należy zauważyć, że Gałuszka podejmuje ważne i trudne zagadnienie, choć nim przedstawione zostają wyniki badań, to naświetleniu ulegają przyjęta metodologia i terminologia, a także kwestia szeroko rozumianej edukacji medialnej w świetle medium gier wideo. O ile metodologia socjologiczna nie wzbudza zastrzeżeń (co więcej, jest zrozumiała i zastosowana

4 Należy jednak podkreślić, że od momentu komercyjnego sukcesu gry Wiedźmin 3. Dziki Gon (CD Projekt Red, 2015) polski rząd regularnie wspiera developerów gier oraz organizuje kampanie i liczne akcje namawiające do nauki programowania i tworzenia gier (Radzewicz, 2017). 
w sposób logiczny, co Gałuszka udowadnia swoim wywodem), o tyle zastanawiająca jest część groznawcza przedstawionych rozważań.

Początkowo autor zarysowuje znaczenie gier wideo w kontekście ludyczności, tak bliskiej człowiekowi niezależnie od epoki, w której ten żyje, a później przedstawia ważne daty $\mathrm{z}$ historii komputeryzacji, by szybko przejść do rozważań o znaczeniu gier we współczesnej mediosferze. Problem jednak w tym, że o ile perspektywa ta jest nakreślona w miarę przejrzyście, o tyle później następuje próba nakierowania spojrzenia czytelnika na kwestię edukacji medialnej z uwzględnieniem tzw. cyfrowego rodzicielstwa. Brakuje w publikacji Gałuszki szerszego aparatu z zakresu groznawstwa, czy mówiąc ogólniej, game studies jako takich, co służyłoby uzupełnieniu ujęcia stricte socjologicznego. Wykorzystując, zresztą bardzo płynnie, właśnie pojęcia socjologiczne i koncentrując się głównie na tej dziedzinie, autor zdaje się wpadać w pułapkę podkreślania przeważnie negatywnego nacechowania gier (podpiera się przy tym ratingiem PEGI czy przykładem gier przeznaczonych dla osób dorosłych, np. seriami Call of Duty czy Grand Theft Auto). Nierzadko wskazuje również na gry wideo jako źródło uzależnień i motywatory agresji. Jest to powtarzanie utartych stereotypów, choć sam autor wielokrotnie stara się niejako "tłumaczyć" z tego, że nie chce traktować gier jedynie jako mediów niedostosowanych do młodych odbiorców czy wzbudzających agresję. Ponadto fakt przywoływania efektów negatywnych z pominięciem niejako oczywistych elementów pozytywnych, związanych z popularnością gier MMO (Massive Multiplayer Online) czy trybów multiplayer, takich jak aspekt komunikacyjny i socjalizujący graczy (Marak, Markocki, 2016, s. 52-62), wydaje się perspektywą wygodną. Autor co prawda powołuje się na teksty wydane w dość dużym odstępie czasu (m.in. lata 2006, 2012 i 2016), jednak jego punkt widzenia jest dyskusyjny w odniesieniu do tak szybko zmieniającego się medium, zwłaszcza biorąc pod uwagę przemianę branży gier zachodzącą obecnie, pod koniec drugiej dekady XXI wieku ${ }^{5}$. Tak samo problematyczny wydaje się brak wzmianki o grach mobilnych, popularnych $\mathrm{w}$ dzisiejszym świecie przede wszystkim z racji darmowej rozgrywki (tzw. format free to play) oraz łatwej dostępności sprzętowej (wystarczy smartfon; konsola czy drogi komputer stacjonarny nie są potrzebne). Ponieważ współczesny rynek gier mobilnych, jako ten oparty na modelu free to play,

5 Chodzi o przemiany związane $\mathrm{z}$ fabułocentrycznością i skupieniem się na narracji produkowanych gier, a także $\mathrm{z}$ nastawieniem procesu projektowania gier pod kątem emocji gracza, które mają wpływać na pogłębioną immersję oraz zachowywać odpowiednią retencję. Zmiany te widoczne są zarówno w grach komputerowych i konsolowych, jak i produkcjach przeznaczonych na urządzenia mobilne. 
jest jednym z największych oraz najłatwiej dostępnych (Mediakix, 2018), jego nieuwzględnienie wydaje się wyraźnym brakiem w publikacji. Sam Gałuszka (2017) tłumaczy się z przyjętej przez siebie perspektywy w sposób następujący:

Nie stawiam gier w centrum problemu badawczego, nie skupiam się na formie czy strukturze medium, lecz ważne są dla mnie zjawiska towarzyszące grom: praktyki ich wykorzystania w rodzinach, ich potencjał socjalizacyjny i wychowawczy. Zwracam uwagę na sytuację grania i samych graczy. Podkreślam funkcję gier wideo w tak ważnej sferze życia społecznego jak życie rodzinne. Pokazuję możliwości gier - zarówno pozytywne, jak i negatywne - i poszerzam pole ich zastosowań do roli narzędzia wychowawczego. W efekcie, jak mi się zdaje, wyciągam wspominanego „olbrzyma z cienia” i umiejscawiam go pośród podstawowych procesów wewnątrzrodzinnych, tym samym nadając grom istotny społeczny kontekst. To wszystko sprawia, że moje rozważania łączą podstawowy przedmiot badań groznawczych z kluczowymi obszarami zainteresowania socjologii, pedagogiki, psychologii czy nauk o mediach (s. 88).

Wydaje się jednak, iż autor, mimo deklaracji o skupieniu się na socjologii i rodzinie, próbuje koncentrować się na grach, przez co niekiedy można stracić poczucie, co jest właściwym celem publikacji - czy uzmysłowienie, że gry są medium ważnym i wszechobecnym, które egzystuje również w podstawowej komórce społecznej, jaką jest rodzina; czy może - zwrócenie uwagi, iż w tejże komórce gry w ogóle mogą także egzystować. Obie perspektywy, choć są nieco podobne, w rzeczywistości różnią się od siebie.

Istotnym elementem, wielokrotnie powtarzającym się w książce Gry wideo $w$ środowisku rodzinnym, jest wątek edukacji medialnej, będącej niejako osią rozważań autora. Gałuszka zwraca uwagę, słusznie zresztą, na braki w cyfrowej edukacji oraz w edukacji medialnej w ogóle - zarówno u rodziców, jak i u dzieci. Wydaje się, że trafnie diagnozuje problem, analizując nie tylko jego charakter, lecz także dotkliwe konsekwencje. Przy tym podkreśla, powołując się na wyniki przeprowadzonych przez siebie badań, m.in. nieumiejętność analizowania przez rodziców tego, co widzą na ekranie. Nie chodzi tylko o brak wiedzy kontekstowej, ale o rozumienie tego, na co właściwie się patrzy. Gałuszka zwraca uwagę na kilka innych tego rodzaju problematycznych kwestii, przez co zrozumiała jest postulowana przez niego potrzeba wykształcenia edukatorów medialnych i, ogólniej, popularyzowania samej edukacji medialnej. Dobrze wpisuje się w to metafora muru dzielącego rodziców i dzieci, jakim są nowe technologie, w tym gry, czy - mówiąc szerzej - różnica pokoleń i sposobów komunikacji. Autor postuluje, by to właśnie multimedialna rozrywka stanowiła taką wyrwę w murze, gdyż może okazać się płaszczyzną kontaktu 
oraz wspólnego spędzania przez rodziców czasu z ich pociechami. Jednocześnie sam zdaje się podkreślać nieustannie fakt, iż to właśnie gry wideo kreują ten mur i rodzice niewiele robią, by go zburzyć. Gałuszka, bazując na przeprowadzonych przez siebie badaniach, ale również na podstawie zebranych materiałów, np. raportów oraz innych publikacji naukowych, rysuje obraz polskiego rodzica jako wycofanego i zagubionego, niezwykle biernego i pasywnego, takiego, który nie stara się dążyć do powiększenia wyrw we wspomnianym wcześniej murze. Nakreślony przez autora obraz zdaje się idealnie wpasowywać $\mathrm{w}$ awizowaną wielokrotnie w książce potrzebę edukacji medialnej. Warte odnotowania są także trudności, jakie dostrzega autor zarówno w procesie samej edukacji rodziców i dzieci, jak i w popularyzowaniu edukacji medialnej. Wobec tego przeprowadzone przez niego badania, choć stanowiące zaledwie wycinek szerszego obrazu, zdają się potwierdzać potrzebę edukacji, powszechnego uświadamiania oraz dialogu - o grach wideo, czasie wolnym i rozrywce dzieci, lecz przede wszystkim o relacjach między rodzicami a dziećmi. Gałuszka przedstawia swoje spostrzeżenia, wedle których gry mogą w tym pomóc.

Mówiąc o tych spostrzeżeniach, należy zwrócić uwagę na całokształt przeprowadzonych analiz. Przede wszystkim badania jakościowe, na które zdecydował się autor, ukazują nie tylko wiedzę rodziców na temat ich dzieci - graczy, lecz przede wszystkim obnażają niewiedzę dorosłych. Oczywiście, jest to jeden z wniosków wynikających z naukowej refleksji, jednak już przy samym ich formułowaniu Gałuszka wykazuje się dużą ostrożnością i dobitną świadomością tego, że nie zawsze przyjęty model analityczny jest wystarczający. Innymi słowy, autor imponuje samoświadomością badawczą, wskazując możliwe problemy i ostrzegając przed nadinterpretacją wyników. Dzięki temu Gałuszka pozwala - mimo dość niewielkiej próby badawczej - spojrzeć z dystansem na zaprezentowane wyniki, które, choć są pochodną badań jakościowych, autor próbuje potraktować przede wszystkim holistycznie. Holistyczność w wypadku Gier wideo w środowisku rodzinnym oznacza zwłaszcza zwrócenie uwagi na inne problemy badawcze oraz kwestie zasługujące na szerszą refleksję nie tylko naukową, lecz także specjalistyczną, być może nawet - terapeutyczną. W tym miejscu warto uwypuklić wyjątkowy atut publikacji - to przyczynek do kolejnych rozważań, który można by określić mianem znaku ostrzegawczego dla medioznawców i specjalistów od tematyki rodziny, a także wskazanie, nad jakimi zagadnieniami należy się pochylić w pracy edukacyjnej.

Warto jednak podkreślić (i uznać za jeden z największych sukcesów autora w tej publikacji), że badacz nie pozwala czytelnikowi wpaść w pułapkę fałszywego obrazu. Świadomość problematyczności czy to metody, czy liczby respondentów jest u Gałuszki bardzo wysoka, dzięki czemu w odpowiedni sposób 
prowadzi on tok myślowy i modeluje możliwe postrzeganie swoich badań. Nie oznacza to jednak, że książka wolna jest od kwestii jeśli nie problematycznych, to co najmniej zastanawiających. Jedną z nich jest grupa odbiorcza. Gałuszka (2017) pisze w o tym ten sposób:

[...] podejście badawcze ogranicza potencjał eksplanacyjny przedstawianego tekstu, jednak uważam to za niezbędny koszt przygotowania projektu, którego efekty są skierowane przede wszystkim do grup, których przeprowadzone badania dotyczą - co jednocześnie wpisuje prezentowaną pracę w nurt socjologii zaangażowanej (s. 17).

Podejście takie wydaje się zrozumiałe, może się wpisywać w koncepcję narzędzia czy formy pomocy, zwłaszcza dla rodziców, jak było to już wspomniane. Jednakże nieco później autor kontynuuje:

Prezentowana publikacja skierowana jest do szerokiej grupy odbiorców. Liczę, że zyska ona uznanie naukowców (w szczególności związanych z pedagogiką i socjologią rodziny oraz nowych mediów), ale też studentów, nauczycieli, przedstawicieli instytucji kultury, osób powiązanych z projektami edukacyjnymi i kulturalnymi, a także rodziców. Jednocześnie zdaję sobie sprawę z ryzyka tak szeroko ustawionej grupy odbiorców, ponieważ wiąże się to z koniecznością stosowania kompromisowych rozwiązań, np. unikania przesadnego teoretyzowania. $Z$ tego powodu książka ta co prawda nie wyczerpuje podjętej problematyki z racji jej złożoności (co może być problematyczne dla części ekspertów i teoretyków), jednak stanowi pierwszy tak wyraźny krok w stronę opisania konsekwencji obecności gier cyfrowych w życiu polskich rodzin, jednocześnie wychodząc poza wymiar czysto diagnostyczny (co z kolei powinno wpisać się w potrzeby osób nastawionych praktycznie, w tym rodziców) (Gałuszka, 2017, s. 18).

Ten długi cytat ukazuje rzecz jasna szerokie zastosowanie publikacji, ale właściwie potwierdza problem dotyczący tego, do kogo praca Gałuszki jest skierowana. Autor słusznie zwraca uwagę na złożoność problematyki i unikanie teoretyzowania (choć to akurat jest argument przesadny), bo w istocie przedmiot badań jest co najmniej wieloznaczny. Wydaje się jednak, że próbując dotrzeć do tak szerokiej grupy odbiorców, Gałuszka niekoniecznie musi trafić do socjologów nowych mediów czy edukatorów, dla których praca ta może być jedynie katalizatorem stymulującym dalszą refleksję, nie zaś toolkitem, jak chciałby autor. Kolejną niejednoznaczną kwestią są stereotypy na temat gier, mocno zaakcentowane w książce. Pojawiają się one zarówno w wypowiedziach rodziców, jak i w moralizującym niekiedy tonie autora, krytykującego postawę wobec 
ograniczeń wiekowych czy korzystanie z gier „dla dorosłych” przez dzieci. I na pozór nie ma w tym nic złego, jednak biorąc pod uwagę specyfikę medium, nie sposób nie odnieść wrażenia, że Gałuszka traktuje jako złe te produkcje, które są modne i ciekawe, zatem $z$ dużą dozą prawdopodobieństwa można przypuścić, iż sięgnie po nie młody odbiorca, dla którego nie są one przeznaczone. Jednocześnie autor sam niekiedy próbuje się wybronić ze stereotypowego myślenia i wskazuje, że nawet gry z ratingiem $18+$ można zastosować w pracy z młodzieżą, jednak używa przy tym przekonujących argumentów. W związku z tym komponent argumentacyjny jest tutaj dość niejednoznaczny, a prawdopodobną przyczyną jest brak opisu rzeczywistych praktyk dystrybucyjnych lub chociaż zarysowania społecznego oddziaływania gier wideo jako przykuwających uwagę i kreujących specyficzne potrzeby, także u młodych odbiorców. Ponadto warto byłoby również poświęcić miejsce zagadnieniu niejednokrotnie pomijanemu zarówno przez badaczy gier, jak i socjologów - temu, co tak naprawdę widzi gracz w toku rozgrywki, a co widzi osoba obserwująca samą grę. Wydaje się, że ta swoista różnica perspektyw byłaby przydatna rodzicom oraz innym potencjalnym odbiorcom do nakreślenia, dlaczego właściwie młodzież i dzieci grają w gry dla nich nieodpowiednie. W tym momencie rozwoju branży oraz wiedzy o graczach odpowiedź oparta na kategorii „treści nieodpowiednich" wydaje się po prostu niewystarczająca.

Niezależnie od tego, dużym walorem pracy Gałuszki, poza samą analizą badań, jest część poświęcona pracy z rodzicami i roli edukacji nieformalnej. Autor celnie diagnozuje problemy nie tylko współczesnej rodziny, lecz także relacji między dziećmi a rodzicami w ogóle; szczególnie surowy jest przede wszystkim wobec tych drugich, których to jego zdaniem należy skłonić do pracy nad relacją z pociechami i chęcią poznania ich świata (jak można określić gry wideo). Ta perspektywa, choć może niekoniecznie naukowa, jest, niestety, po prostu prawdziwa, chociaż nie należy tutaj generalizować. Przypadki, w których gry traktowane są jako artefakt wyobrażonego „świata dzieci”, coś infantylnego i niepoważnego, wciąż się zdarzają, choć rzecz ta ulega, na szczęście, zmianie.

Istotnym komponentem rozprawy jest również zwrócenie uwagi czytelnika na potencjał edukacyjny gier w ogóle. Gałuszka zwięźle i trafnie opisuje elementy gier, które można w wartościowy sposób wykorzystać. W tym aspekcie autor doskonale realizuje swój cel - tutaj jego książka w pełni okazuje się swoistym przewodnikiem dla edukatorów, ale przede wszystkim dla rodziców, którzy dzięki własnemu zaangażowaniu i grom mogą zbudować z dziećmi mocną więź i przy tej okazji również wiele je nauczyć. Dotyczy to także potencjalnych zagrożeń, wśród których badacz wskazuje niewiedzę rodziców czy 
ich uśpioną czujność, punktując tym samym dorosłych za bierność oraz częsty brak zainteresowania życiem własnych pociech. Niezwykle frapująca wydaje się tutaj proponowana koncepcja wykorzystywania gier dla dorosłych poprzez zaangażowane współuczestnictwo i wspólne granie rodzica z dzieckiem. Autor celnie typuje takie doświadczenie jako okazję do nauki licznych kontekstów, wszystko to jednak wymaga zmasowanej pracy samego rodzica. To właśnie ona staje się najtrudniejszym do rozwiązania problemem, na jaki wskazuje autor. Dlatego też wartościowe są propozycje Gałuszki dotyczące sposobów pracy z rodzicem, czy wręcz gotowe scenariusze warsztatów, które mogłyby inicjować edukację medialną rodziców w zależności od ich świadomości i wiedzy na temat multimedialnej rozrywki. Jest to kolejny atut książki, choć w rzeczywistości nie jest ona przeznaczona wyłącznie dla rodziców, a również dla osób pracujących z nimi.

Nieco dyskusyjne mogą wydawać się z kolei Propozycje dobrych praktyk rodzicielskich, jakie oferuje autor. Oczywiście, są to tylko sugestie. Trudno oprzeć się wrażeniu, że niekiedy ponownie celują one w bierność i nieświadomość rodziców, a czasami nakłaniają do przesadnej kontroli, nie zaś do zaangażowanej relacji z dzieckiem. Niektóre jednak wskazówki, choć nie mówią tego wprost, nakłaniają do czegoś, co wydaje się jedną z największych trudności, z jakimi boryka się współczesna rodzina - do interakcji rodzica $\mathrm{z}$ jego pociechą. Wymownie opisuje to jedna z proponowanych praktyk:

Należy pamiętać o specyfice gier wideo, szczególnie w kontekście kontroli ich wykorzystywania. Dziesięć minut obserwacji może być wystarczające w przypadku prostej gry wyścigowej, ale ten sam czas przyglądania się rozbudowanej grze akcji może dać jedynie złudny - bo mocno fragmentaryczny - obraz pełni rozgrywki. Dlatego warto, aby rodzic poprosił dziecko o przedstawienie możliwości gry, zapytał o obecne w produkcji uzbrojenie czy postaci, a także zasugerował interakcję z wybranymi bohaterami. Najlepszym rozwiązaniem byłoby tutaj samodzielne przejście fragmentu gry, połączone z lekturą opisów umieszczonych na stronach PEGI. Skuteczną alternatywą jest przejrzenie zapisu rozgrywki na portalu YouTube. Zazwyczaj wystarczy wpisanie w wyszukiwarce tytułu gry wraz z frazą „let's play”, „zagrajmy” lub „gameplay” (Gałuszka, 2017, s. 220-221).

Z jednej strony Gałuszka sugeruje czujność, a z drugiej wskazuje na potrzebę zaangażowania, wspólnego doświadczenia, przeżywania i interakcji. Choć, prawdę powiedziawszy, można odnieść wrażenie, że autor przekonuje rodziców do prawidłowych praktyk rodzicielskich, do... bycia rodzicem i w ogóle zainteresowania się światem własnego dziecka. I o ile jest to postawa jak najbardziej słuszna, to w szerszej perspektywie jest to dość smutne, ponieważ 
zwraca uwagę na fakt, iż nierzadko rodzice nie wykazują najmniejszego zainteresowania swoimi pociechami oraz tym, jak spędzają one wolny czas.

Niemniej również w tych rozważaniach brakuje dość istotnej kwestii atrakcyjności samej branży gier wideo oraz multimedialnej rozrywki. Obecnie świadomość funkcjonowania gier u dzieci jest znacznie większa. Uczniowie chcą mieć zajęcia z programowania, w szkołach prowadzone są zajęcia dotyczące gier wideo, szkolne ligi, np. League of Legends (Riot Games, 2009), popularny jest e-sport. Zmienia się również świadomość samych dzieci i młodzieży odnośnie do gier. Młodzi ludzie już nie tylko chcą grać, ale także pracować $\mathrm{w}$ przemyśle multimedialnej rozrywki. A to z kolei wpływa na czas, ogrywane tytuły i podejście do całego zagadnienia. Tej perspektywy w pracy Gałuszki ewidentnie zabrakło i choć nie ona jest głównym tematem, to w obliczu tak intensywnego nastawienia rządu i polskiej gospodarki na produkcję gier wzmianka o tym oraz próba zmierzenia się z tą kwestią byłyby wskazane. Nie zmienia to jednak postaci rzeczy, że książka Gałuszki pt. Gry wideo $w$ środowisku rodzinnym. Diagnoza i rekomendacje to publikacja wartościowa i ciekawa $\mathrm{z}$ wielu powodów. Jest to nie tylko próba zbadania, jak gry wideo są postrzegane przez rodziców i jaką rolę w rzeczywistości odgrywają w polskiej rodzinie, lecz także próba refleksji o owej komórce społecznej w dobie ekspansji multimedialnej rozrywki w ogóle. Przede wszystkim jest to jednak zaczątek, wskazówka i drogowskaz do dalszych badań, ponieważ o ile autor pytań (nie zawsze wypowiedzianych wprost) zadaje całkiem sporo, o tyle bardziej skłania czytelnika do refleksji (również badawczej!) niż sam daje odpowiedzi. Nakierowuje, ale nie prowadzi, dzięki czemu odbiorca sam ma możliwość osądzić, czy gry w takim ujęciu faktycznie mogą być „wyrwą w murze” relacji rodzinnych.

\section{Bibliografia}

Bobrowski, M., Rudzińska-Szary, P., Krampus-Sepielak, A., Śliwiński, M., Rudnicki, S. (2017). Kondycja polskiej branży gier '17. Raport 2017. Kraków: Krakowski Park Technologiczny. Pobrane z: http://www.kpt.krakow.pl/wp-content/uploads/2018/03/kondycja-polskiej-branzy-gier17.pdf.

CD Projekt RED. (2015). Wiedźmin 3. Dziki Gon [gra wideo]. Warszawa: CDP.PL.

DiGRA. (b.d.). About us. Pobrane z: http://www.digra.org/the-association/about-us/.

Gałuszka, D. (2017). Gry wideo w środowisku rodzinnym. Diagnoza i rekomendacje. Kraków: Wydawnictwo Libron.

Lenhart, A., Kahne, J., Middaugh, E., Macgill, A. R., Evans, C., Vitak, J. (2008). Teens, video games, and civics: Teens' gaming experiences are diverse and include 
significant social interaction and civic engagement. Pobrane z: http://www.pewinternet.org/2008/09/16/teens-video-games-and-civics/.

Marak, K., Markocki, M. (2016). Aspekty funkcjonowania gier cyfrowych we współczesnej kulturze. Studia przypadków. Toruń: WN UMK.

Marczak, G. (2018, 17 września). Kraśko i Rusin w żenującej rozmowie w TVN o esporcie. Pobrane z: https://antyweb.pl/tvn-program-o-esport/.

Mediakix. (2018). The mobile gaming industry: Statics, revenue, demographics and more. Pobrane z: http://mediakix.com/2018/03/mobile-gaming-industry-statistics-market-revenue/\#gs.b948RPc.

Michael, D. R., Chen, S. (2005). Serious games: Games that educate, train, and inform. Boston, MA: Muska \& Lipman, Premier-Trade.

Radzewicz, M. (2017). Kampania społeczna Programuj. Pobrane z: https://www.spidersweb.pl/2017/02/kampania-spoleczna-programuj-gov-pl.html.

Riot Games. (2017). League of legends. Culver City, CA: Riot Games. 